\title{
Pronounced Dead
}

National Cancer Institute

\section{Source}

National Cancer Institute. Pronounced Dead. NCI Thesaurus. Code C99799.

The status of an individual is officially declared not living by an authority. 